\title{
Design and Development of a Hazard Identification Tool for Laboratory Fire Risk Assessment using Delphi Technique
}

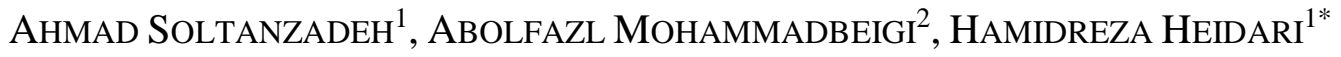 \\ ${ }^{*}$ Department of Occupational Health \& Safety Engineering, Research Center for Environmental Pollutants, \\ Faculty of Health, Qom University of Medical Sciences, Qom, Iran \\ ${ }^{2}$ Department of Biostatistics \& Epidemiology, Research Center for Environmental Pollutants, Faculty of Health, \\ Qom University of Medical Sciences, Qom, Iran
}

Received February 07, 2021; Revised May 29, 2021; Accepted July 25, 2021

This paper is available on-line at http://ijoh.tums.ac.ir

\begin{abstract}
The prevalence of fire in laboratories is high due to the potential sources of the fire hazards, including the use of various equipment and chemicals, as well as the possibility of human error. Accordingly, this study was designed and conducted with the aim of developing a tool to identify hazards and assess laboratory fire risk. In the present study, we used the Delphi technique in three rounds in 2020 with the participation of 17 experts in the fields of safety engineering, occupational health engineering, chemistry, and chemical engineering. The scattering index of coefficient of variation (CV) was higher than $20 \%$ and the acceptance criterion for each item was considered with an average of $\geq 4$. In addition, the validity and reliability of this tool were evaluated using content validity ratio (CVR), content validity index (CVI), and Cronbach's alpha reliability index. After three rounds of Delphi study, the hazard identification and risk assessment questionnaire for laboratory fire were developed with 45 items, including chemical materials and compounds, electricity, and fire response. The coefficient of variation (CV) in this Delphi study was equal to 0.05 . The results of the validity and reliability evaluation of this tool showed that the content validity index (CVI) and Cronbach's alpha coefficient were equal to 0.902 and 0.88 . The questionnaire of the present study indicated an acceptable validity and reliability for identifying hazards and assessing laboratory fire risk. Therefore, this tool provided a quick, easy, and practical way to identify hazards and assess the risk of laboratory fires.
\end{abstract}

KEYWORDS: Laboratory; Hazard identification; Fire; Fire Risk Assessment; Delphi technique.

\section{INTRODUCTION}

A laboratory is an environment for performing various activities, including various measurements, experimental tests, analysis, quantification, and quality control with objectives such as training, manufacturing and product control, implementation of national standards, and provide services such as health, industrial and research services. In addition, science in various fields has experienced an improvement trend during the past

Corresponding author: Hamidreza Heidari

E-mail:Hr.heidari.tums@gmail.com
decades.Hence, it is of particular importance to perform various experiments to find out the answers to the questions and hypotheses. Therefore, with the development of these sciences, we need equipped and safe places to conduct experiments [1-2]. On the other hand, there is an ascending trend in the number of dangerous and even fatal accidents in various laboratories. So, risks identification in laboratories to create safe conditions is very important [3-4]. Due to the 
nature, processes, and different activities in laboratories, it is possible to encounter various harmful chemical, biological, and accidental factors. The most important impact of these factors is the occurrence of fire due to the exposure and use of various chemical substances and compounds. Moreover, complex devices and equipment's risks of using and special working methods will probably accompany the fire risks and electrical shocks [4].

The results of previous studies showed that the possibility of occupational accidents such as fires in laboratories is high. For example, the explosion of a hydrogen capsule in the laboratory of Tarbiat Modares University in Tehran [5-6]. There is a record of 21 university laboratories accidents in Taiwan between the years 1997 and 2004 [7]. It could be due to less experience, skill, and knowledge level of students while they are working with hazardous material or sensitive equipment. Therefore, safety and health measures should be completely followed to decrease accidents and financial losses.

In a study, laboratories of a research institute were assessed using the Failure Mode and Effect Analysis (FMEA), the results showed that the level of risk in most of the studied laboratories was semi-critical and critical [3]. Similarly, the results of a study in health, safety, and environmental risk assessment in hospitals showed that the highest risk priority number was related to the biological factors and the lowest one was related to the physical factors affecting humans [8].

Different methods of risk assessment have been applied to evaluate the risks of laboratories evaluated from different perspectives so far. So, each of them has identified certain potential or actual risks and the amount of risk. However, in many cases, researchers have not been focused on evaluating such environments or specific hazards such as fire hazards, electrical hazards, construction hazards, and so on [9$11]$.

Therefore, considering the existence of legal requirements based on hazard control in the workplace, as well as the importance of the challenge and risk of fire in laboratory settings, the present study was aimed to develop a tool to identify hazards and assess fire risk in the laboratory.

\section{METHODS}

This cross-sectional study was conducted based on the Delphi technique and expert opinions in 2020.

\section{Designing tool for identifying hazards and assessing laboratory fire risk:}

A tool to identify hazards and assess the risk of laboratory fires was designed and developed based on a comprehensive literature review. Thus, different sources were screened to get a broad view about the issue using the electronic databases including PubMed, Scopus, Science Direct, and Web of Science, and Google scholar. So, in this study, we filter out only English and Persian published journal articles for review. In this sense, we applied combinations of the search terms, including hazard identification; fire, fire risk assessment, Delphi technique, and risk factor in the automated searches. References and citations of the selected articles were inspected to ensure the inclusion of all relevant articles.

According to the objectives of the study and important areas in this field, including types of hazards, events and consequences, injuries, as well as safetythreatening risk factors in the laboratory [4-12-14], a primary tool based on three areas and 50 items was developed. These three areas included (1): chemical substances and compounds (20 items), (2): electricity (10 items), and (3): fire reaction (20 items). This tool was developed during three rounds of the Delphi study using the panel of experts' opinions.

\section{Development of hazard identification questionnaire and laboratory fire risk assessment based on the Delphi technique:}

The Delphi technique is a useful method to reach a consensus in group decision-making. In Delphi studies, participants have knowledge and awareness about the subject [15-16]. The Delphi technique is a structured process method to determine the most reliable situation based on the experts' opinions in each scientific field. Therefore, unlike survey research methods, the validity of the Delphi method does not depend on the number of participants in the research but the scientific validity of the experts participating in 
the study. The number of participants in the Delphi study varies from 5 to 20 individuals [17].

In the current study, 17 specialists participated with bachelor, master, and doctoral degrees in the fields related to the study subject, including safety engineering, occupational health engineering, chemistry, and chemical engineering. This Delphi study was conducted in three rounds as follow:

\section{The first round of Delphi:}

In this round, 17 experts in the panel of experts were asked to comment on the desirability of areas and items presented based on the Likert scale of five options (very low to very high). In addition, they were asked to submit suggestions, if an area or item needs to be added for better hazards identifying and assessing the laboratory's fire risk. Then, the results of the first round of the Delphi study were analyzed.

\section{The second round of Delphi:}

In the second round, After collecting the opinions of experts and analyzing the results of the first round of the Delphi, possible changes based on the opinions of experts were implemented in the designed questionnaire and sent to the experts' panel for collecting additional comments. In this round, the participating experts were asked to comment again on the desirability of the presented items. In addition, they were asked again to submit suggestions, if an area or item needs to be added for better hazards identifying and assessing the laboratory's fire risk. Then, the results of the second round of the Delphi study were analyzed.

\section{The third round of Delphi:}

In the third round and after analyzing the results of the second round of this study considering possible changes, a laboratory fire hazard identification and risk assessment questionnaire was sent to the panel of experts to re-comment on the desirability of items in this tool. After collecting the opinions of experts in the third round and analyzing the data and considering the lack of relative change based on the coefficient of variation $(\mathrm{CV})$ compared to the second round (>20\%), this Delphi study ended and the laboratory hazard identification and risk assessment questionnaire were developed based on the Delphi technique. It is noteworthy that the acceptance criteria of each component and parameters for this Delphi study were considered with an average of $\leq 4$ [18].

\section{Validity and reliability assessment:}

The validity and reliability of the questionnaire were assessed using the Content Validity Index (CVI) and the Cronbach's alpha coefficient. The content validity index (CVI) was used to assess the validity of the questionnaire. To calculate CVI, experts were asked to rate how relevant each item is [19-20]. If the calculated value was less than 0.7 , the item was rejected, if it was between 0.7 to 0.79 , it should be reviewed and if it was greater than 0.79 , it was acceptable.

In addition, the reliability of a questionnaire was assessed using Cronbach's alpha coefficient. The Cronbach's alpha was used to measure the onedimensionality of attitudes, judgments, and other categories that were not easy to measure (Equation 1). Where, $\alpha \geq 0.7$ was acceptable and $\alpha \geq 0.9$ was excellent [21-22].

$\boldsymbol{\alpha}=\left(\frac{k}{k-1}\right) \times\left(1-\frac{\sum_{i=1}^{k} s_{i}^{2}}{s_{t}^{2}}\right)$

Where:

$\alpha:$ Reliability

$k:$ Number of items / questions

$s i^{2}:$ The variance of each item / question

$s t^{2}:$ Total variance of items / questions

\section{RESULTS}

This Delphi study was conducted to develop a hazard identification tool and fire risk assessment in the laboratory. The literature review was conducted to identify 73 potentially relevant records from four different databases and their references during the initial searches. After removing duplicate studies via Endnote software, 52 articles remained for screening based on the title and abstract. During the screening process, 16 records were removed by checking the title and abstract and 36 records were assessed by full text. In evaluating the full text of the article, 17 full texts were removed and finally, 19 full-text articles were assessed in this study in order to identify types of hazards, events, and consequences, injuries, as well as safety-threatening risk factors related to fire risks in the laboratories. 
Demographic characteristics of the panel of experts showed that the mean and standard deviations of the age and work experience of these specialists were $37.78 \pm 3.26$ and $9.425 \pm 3.55$ years, respectively. The study of these characteristics showed that $35.3 \%$ of the subjects were females and $64.7 \%$ of the panel of experts were males. Evaluation of marital status of these specialists showed that 4 people were single and 13 people were married. In addition, $23.53 \%$ had a bachelor's degree, $52.94 \%$ master's degree, and $23.53 \%$ had a doctoral degree. The panel of experts had the specialties of safety engineering ( 2 people), occupational health engineering ( 7 people), chemistry (6 people), and chemical engineering ( 2 people), (Table 1).

Table 1. Individual and demographic characteristics of the specialists in the study $(n=17)$

\begin{tabular}{ccc}
\hline Parameter & Categories & Value \\
\hline Age (year) & - & $37.78 \pm 3.26$ \\
Work experience & - & $9.42 \pm 3.25$ \\
Gender & Female & $6(35.30 \%)$ \\
& Male & $11(64.70 \%)$ \\
Marital status & Single & $4(23.53 \%)$ \\
& Married & $13(76.47 \%)$ \\
Education & Bachelor & $4(23.53 \%)$ \\
& Masters & $9(53.94 \%)$ \\
& Doctorate & $4(23.53 \%)$ \\
Specialty & Safety Engineering & $2(11.76 \%)$ \\
& Occupational Health Engineering & $7(41.18 \%)$ \\
& Chemistry & $6(35.30 \%)$ \\
\hline
\end{tabular}

The results of the first round of the Delphi study showed that all members of the panel of experts provided their answers based on the desirability/desirability of the items of questionnaire (participation rate $=100 \%$ ). In addition, some panel members suggested some items for the questionnaire. The four items in the field of electricity were recommended, including: (1): Having the laboratory personnel received the necessary training on electrical safety and first aid? (2): Is the door of the electrical panel always kept closed?, (3): Are there electrical panels safe? and (4): Is there a proper heating system used on site?. In the scope of the fire response two recommendations were suggested, including: (1): Have fire extinguishers a Persian catalog? and (2): Are fire extinguishers easily visible?. In addition, some experts suggested that some items could be merged.

After applying these changes in the primary tool based on the expert's opinions in the first round (adding and merging suggested items), the second round of the Delphi study was conducted. In the second round, the 
expert's panel had no new suggested items for this tool. The participation rate for this round was $100 \%$. To assess the reliability of the responses provided by the panel of experts in the second round, in the third round of the Delphi study, these individuals were again asked to comment on the questionnaire's items. The results of the third round of the Delphi showed that the CV index was 0.05 compared to the second round and this value was much lower than the standard value considered for this study (> 20\%). Finally, according to this scatter index (CV), the Delphi study was completed at this stage. At the end of the third round of the Delphi study, based on the acceptance criteria for each item, including the agreement of $75 \%$ of experts, 11 items were removed. Finally, the questionnaire was developed including three areas and 45 items (see Table 2).

The results of the validity assessment of this tool using the experts' opinions showed that the content validity index (CVI) of this questionnaire was 0.902. In addition, the reliability of this questionnaire was 0.88 using Cronbach's alpha coefficient.

It should be noted that the index of the laboratory fire safety and risk, based on this questionnaire was developed and classified in three levels, including weak level or class 1 (final index $\leq 90$ ), medium level or class $2(90<$ final indexes $\leq 180)$, and desirable level or class 3 (final index $>180$ ).

Table 2. Extended hazard identification and risk assessment questionnaire for laboratory fire

\begin{tabular}{|c|c|c|c|c|}
\hline Scopes & Items & $\begin{array}{l}\text { No } \\
(1)\end{array}$ & $\begin{array}{c}\text { Somewhat } \\
\text { (3) }\end{array}$ & $\begin{array}{l}\text { Yes } \\
(5)\end{array}$ \\
\hline 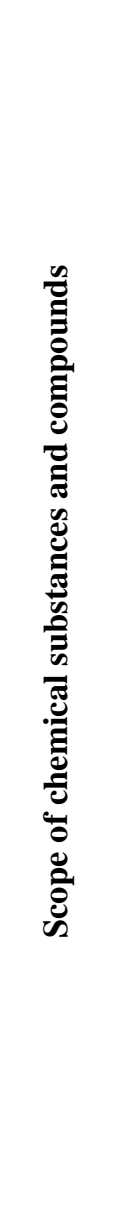 & $\begin{array}{l}\text { 1. Do all chemicals have information labels? } \\
\text { 2. Is SDS available for all chemicals? } \\
\text { 3. Is the storage of extra materials prevented? (More than } \\
\text { usage of one or two years) } \\
\text { 4. Are chemical containers out of the way? } \\
\text { 5. Are chemicals stored away from light and heat sources? } \\
\text { 6. Are flammable and corrosive materials stored in special } \\
\text { cabinets (anti-flammability and anti-corrosion cabinets) } \\
\text { and away from other materials? } \\
\text { 7. Are reactive materials kept away from heat, shock and } \\
\text { friction? } \\
\text { 9re liquids and hazardous substances stored on shelves } \\
\text { below eye level? } \\
\text { 10. Are toxic storage facilities properly ventilated? } \\
\text { 11. Are various people avoided to entering the warehouse? } \\
\text { 12. Are there any warning signs such as (no smoking)? } \\
\text { 13. Is the ventilation in the warehouse appropriate? } \\
\text { 14. Are the floors and walls of the warehouse washable? } \\
\text { 15. Does spilled material collect quickly? } \\
\text { 16. Are stored goods at a safe distance from electrical } \\
\text { appliances? } \\
\text { 17. Is the number and type of manual extinguishers enough? } \\
\text { 18. Are } 5 \text { S observed in store? } \\
\text { 20. Are the materials coded? }\end{array}$ & & & \\
\hline
\end{tabular}


21.

22. Are all electrical appliances such as switches and sockets safe?

23. Are the wires passed through the insulated pipes?

24. Is the fuse in the power path safe?

25. Are electrical repairs done by the Responsible people?

26. Is the power cut off when the equipment is repaired, and the Lock out/Tag out installed?

27. Have laboratory personnel been trained in first aid when electrocuted?

28. Is the laboratory equipped with a ground connection system?

29. Is there an appropriate fire extinguishing system for electrical hazards?

30. Are electrical panels constantly inspected by the person in charge?

31. Are the sockets located correctly (away from water sources) and is the spark plug used?

32.

33. Is the type of fire extinguisher selected according to the type of fire?

34. Is the number and capacity of available fire extinguisher commensurate with the available space?

35. Have fire risk factors been identified?

36. Is the placement of equipment, materials and tools based on reducing the incidence of fire?

37. Are people familiar with how to use fire extinguisher, duties and firefighting operations?

38. Are firebox parameters including number, test interval, etc. appropriate?

39. Is there a temperature detector with a warning sensor?

40. Are cigarettes and incendiary devices prohibited?

41. Are firefighting equipment inspected and serviced on time?

42. Is the proximity of fire sources to fuel and sunlight sources prevented?

43. Are fire extinguishers easily accessible?

44. Is there a regular schedule for visiting fire extinguishers?

45. Are the extinguishers inspected by a trained person?

46. Is the laboratory building equipped with a fire alarm system?

47. Are there the manual call points (MCP) at appropriate intervals? 


\section{DISCUSSION}

In the current study, we seek to design and develop a tool for identifying hazards and assessing laboratory fire risk based on the Delphi technique. The results showed that the tool designed as a hazard identification and risk assessment questionnaire for laboratory fire was a suitable tool. The validity and reliability were significant for this purpose. The results of this study showed that the content validity index of this tool was 0.902 .

Therefore, according to the CVI criteria values, which were acceptable for CVI values greater than 0.79 , this questionnaire had an acceptable and appropriate validity. In addition, considering the calculation of Cronbach's alpha coefficient was equal to $0.88(\alpha \geq 0.7$ indicates the acceptable reliability of the instrument), this questionnaire will provide the appropriate reliability in identifying hazards and assessing the laboratory's fire risk.

In addition, the findings of this Delphi study indicated that the developed tool for identifying hazards and assessing laboratory fire risk was based on three areas and 45 items, including hazards related to chemical substances and compounds (15 items), electricity (10 items), and response to fire (20 items) (see Table 2).

The application of this tool and risk hazards assessment questionnaire identification help to control the highest risks accosted in the laboratories' fire risk. Therefore, if there is enough attention to the three areas of chemical substances and compounds, electricity, and fire response, it can lead to the identification of the most important sources of danger affecting the fire occurrence or contribute to the occurrence and intensification of the consequences of fire [9-23-24].

The laboratory risks have been evaluated from different perspectives with different methods of risk assessment so far and each of them has identified certain potential or actual risks. These methods have also determined the amount of the risks. However, in many cases, researchers have not been specifically designed a tool to evaluate such environments. Therefore, it was necessary to design a comprehensive assessment method that includes the risks associated with laboratory fires, including construction, equipment, environmental, and human hazards.

This method was based on three important areas related to fire risk in laboratories, including chemical substances and compounds, electricity, and fire response. The results of previous studies showed that the use of chemical substances and compounds have led to some catastrophic cause of the laboratories' fire. Therefore, the safety principles of working with chemical substances and compounds should be considered as a first priority in accordance with the most important measures to reduce fire risk in laboratories such as the Global Homogeneous System (GHS) and the standard of fire protection in chemicals laboratories (NFPA 45) [25-26].

In addition, another important dimension in the occurrence and development of fire risk in laboratory environments included electricity and electrical equipment. Failure to observe electrical safety considerations, including grounding, circuit breaks, and other electrical safety systems might result in catastrophic consequences due to fire for different reasons, such as high load and electrical pressure. Therefore, compliance with the relevant standards such as the electrical safety standard for the work environment (NFPA 70E) should be considered as one of the important measures to reduce fire risk in laboratories [27].

\section{CONCLUSION}

The importance of laboratories in research, educational, diagnostic and evaluation applications, etc. brought a lot of attention to the hazards identification and fire risk assessment. Therefore, the findings of this Delphi study, which was based on the experts' panel opinions showed that the designed and developed tool in this study provided a useful tool for identifying hazards and assessing laboratory fire risk. Therefore, it can be concluded that the use of this tool, which is based on three main and important areas related to fire risk in the laboratory, can lead to an acceptable estimate of fire risk in laboratory settings. 


\section{ACKNOWLEDGEMENT}

The authors are very grateful to the research deputy of Qom University of Medical sciences that financially supports this project and all specialists that cooperate with us for design and development of the hazard identification tool. The project was found to be in accordance to the ethical principles and national norms and standards for conducting Human Research in Iran and approved by the ethics committee with the ID of IR.MUQ.REC.1398.144.

\section{CONFLICT OF INTERESTS}

The authors declare that they have no conflict of interests.

\section{CONTRIBUTION OF AUTHORS}

All authors have same contributions to the conception, design of the work, interpretation of data for the work and final approval of the article. 


\section{REFERENCES}

1. Halvani G, Soltani R, Alimohammadi M, Kiani Z. Identification and evaluation laboratory hazards in Yazd University of Medical Sciences by standard checklists. Occup Med Quartly J. 2011; 3(1):21-27.

2. Adl J. Existing hazards and failure in university laboratories. Tehran Uni Med J. 2004; 6(48):252.

3. Pourang N, ESMAEILI F, Ranjbarian $M$. Application of the failure mode and effects analysis for risk assessment in the laboratories of a research center. J Saf Promo Injury Prev. 2017: 97-108.

4. Soltanzadeh A, Mohammadbeigi A, Fahiminia M, Omidi Oskouie A. Safety Risk Assessment in Educational Environments: A Case Study in Qom University of Medical Sciences. Arch of Occup Health. 2020; 4(3):586-593.

5. Dehdashti A HR. Health, safety and environmental risk assessment in an academic laboratory: A case study. Iran Occup Health. 2015; 12(1):66-76.

6. Nouri J, Mansouri N, Abbaspour M, Karbassi A, Omidvari M. Designing a developed model for assessing the disaster induced vulnerability value in educational centers. Saf Sci. 2011; 49(5):679685.

7. Dehdashti A, Hafezi R. Health, safety and environmental risk assessment in an academic laboratory: A case study. Iran Occup Health J. 2015; 12(1):66-76.

8. Omidvari M, Shahbazi D. Assessing and Prioritizing Health Safety and Environment Risk in Hospitals (Case Study: Shahid Beheshti University of Medical Sciences). J Ilam Uni Med Sci. 2016; 24(1):43-54.

9. Rasool SR, Al-Dahhan W, Al-Zuhairi AJ, Hussein F, Rodda KE, Yousif E. Fire and Explosion Hazards expected in a Laboratory. $J$ Lab Chem Edu. 2016; 4.

10. Omidvari M, Mansouri N. Fire and spillage risk assessment pattern in scientific laboratories. Intl J Occup Hygiene. 2014; 6(2):68-74.

11. Omidvari M, Mansouri N, Nouri J. A pattern of fire risk assessment and emergency management in educational center laboratories. Saf Sci. 2015; 73:34-42.

12. Hill DJ, Williams OF, Mizzy DP, Triumph TF, Brennan CR, Mason DC, Lawrence DS. Introduction to laboratory safety for graduate students: An active-learning endeavor. $J$ Chem Edu. 2019; 96(4):652-659.

13. Huston EM, Milligan JA, Powell JR, Smith AM, Neal D, Duval KM, DiNardo MA, Stoddard C, Bell PA, Berning AW, Wipf P. Development of an undergraduate course in chemical laboratory safety through an academic/industrial collaboration. J Chem Edu. 2018; 95(4):577-583.

14. Yu S, Xin H, Jie L, Li-nan D. Discussion on Current Situation and Countermeasures of Fire Safety Management in Petrochemical Laboratory. Chem Engin Design Communi. 2017(6):36.

15. Boulkedid R, Abdoul H, Loustau M, Sibony O, Alberti C. Using and reporting the Delphi method for selecting healthcare quality indicators: a systematic review. PloS One. 2011; 6(6):e20476.

16. Davidson PL. The Delphi technique in doctoral research: Considerations and rationale. Review Higher Edu Self-Learning. 2013; 6(22).

17. De Villiers MR, De Villiers PJ, Kent AP. The Delphi technique in health sciences education research. Med Teacher. 2005; 27(7):639-643.

18. Shi C, Zhang Y, Li C, Li P, Zhu H. Using the Delphi Method to Identify Risk Factors Contributing to Adverse Events in Residential Aged Care Facilities. Risk Manag Healthcare Policy. 2020; 13:523-537.

19. Almanasreh E, Moles R, Chen TF. Evaluation of methods used for estimating content validity. Res in Social and Admin Phar. 2019; 15(2):214-21.

20. Shi J, Mo X, Sun Z. Content validity index in scale development. J Central South Uni Med Sci. 2012; 37(2):152-155.

21. Ekolu S, Quainoo H. Reliability of assessments in engineering education using Cronbach's alpha, KR and split-half methods. Global J Engin Edu. 2019; 21(1):24-29. 
22. Helms JE, Henze KT, Sass TL, Mifsud VA. Treating Cronbach's alpha reliability coefficients as data in counseling research. The Counseling Psychologist. 2006; 34(5):630-660.

23. Armour M-A. Hazardous laboratory chemicals disposal guide. 1 st ed. CRC Press. USA, 1991.

24. Baker FJ, Silverton RE. Introduction to medical laboratory technology. 5 th ed. ButterworthHeinemann, London, Unite kingdom, 2014.

25. Hick S, Butkus B, Perez CM, Michel RN, Communicating facility limitations: Lab design and beyond. in Editor. Book Communicating facility limitations: Lab design and beyond. Amer Chemcal SOC 1155 16TH ST, NW, Washington, DC 20036 USA, 2019.

26. Yazid MFH, Ta GC, Mokhtar M. Classified Chemicals in Accordance with the Globally Harmonized System of Classification and Labeling of Chemicals: Comparison of Lists of the European Union, Japan, Malaysia and New Zealand. Saf and Health at Work. 2020; 11(2):152-158.

27. Keller K. Electrical Safety Code Manual: A Plain Language Guide to National Electrical Code, OSHA and NFPA 70E. Butterworth-Heinemann, Oxford, United Kingdom, 2010. 